\title{
Family processes: Risk, protective and treatment factors for youth at risk for suicide
}

\author{
Guy Diamond $^{\text {a,* }}$, Tamar Kodish ${ }^{\text {b }}$, E. Stephanie Krauthamer Ewing ${ }^{\text {a }}$, Quintin A. Hunt ${ }^{\text {, }}$, \\ Jody M. Russon ${ }^{\mathrm{d}}$
}

${ }^{\text {a }}$ Drexel University, United States of America

${ }^{\mathrm{b}}$ University of California Los Angeles, United States of America

${ }^{\mathrm{c}}$ Brigham Young University, United States of America

${ }^{\mathrm{d}}$ Virginia Tech, United States of America

\section{A B S T R A C T}

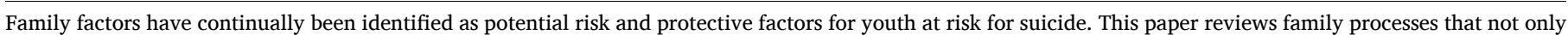

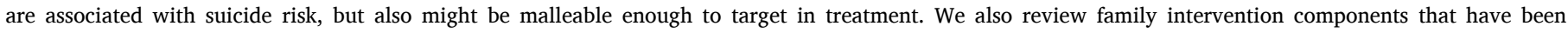

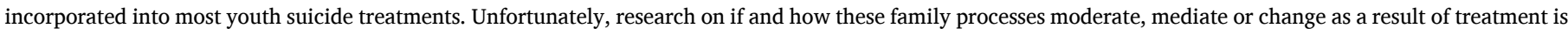
limited. Recommendations for future research are offered.

\section{Introduction}

Suicide is a serious, growing, and multidimensional public health problem in the United States. It is particularly serious in children and adolescents, among whom it is the second leading cause of death for 15to 24-year-olds and the fourth leading cause of death for 5- to 14-yearolds (CDC, 2012). In their lifetime, an estimated $12.1 \%$ of adolescents contemplate suicide, $4.0 \%$ make a plan, and $4.1 \%$ make an attempt. In 20114688 adolescents died by suicide (Hoyert, 2012; Nock et al., 2013). In addition, estimates from 2005 suggest that suicide cost Americans $\$ 26.7$ billion. Of this total, youth and young adults accounted for nearly $\$ 6$ billion of the medical and work loss costs (CDC, 2012). In short, adolescent suicide is a major public health problem, devastating to family survivors, a worrisome burden to medical providers and therapists, and a driver of cost to medical systems. Given the heavy burden of suicide and suicide risk to both society and individuals, identification of effective prevention and interventions for this population is critical (CDC, 2012).

Factors contributing to suicidal risk for adolescents are multifaceted. Extensive research has investigated cognitive, biological, environmental, and social factors (Dimeff \& Linehan, 2001; Fried \& Niesse, 2015; Frey \& Cerel, 2015; Reardon, 2014; Rudd, 2000). One important risk factor consistently associated with adolescent suicidality is the quality of the adolescent-parent relationship(s). Substantial research of community and clinical samples has linked parenting practices and family environment to adolescent suicidal ideation and attempts (Connor \& Rueter, 2006; Kerr, Preuss \& King, 2006; see Wagner et al., 2003 for review). At the same time, family context can be a tremendous protective factor against youth suicide. Studies have indicated that a positive family environment can buffer against the stressors that contribute to youth suicidal ideation and behavior (Resnick et al., 1997; Rubenstein et al., 1998; Zhang \& Jin, 1996). Given the powerful role of family relationships as a risk and protective factor, it is not surprising that most treatments developed and tested for adolescents at risk for suicide have some therapeutic component targeting family factors. In this paper we review many of the mutable family processes that have shown to be associated with youth suicide. We will also describe how family intervention has been incorporated into all the major therapy models for youth suicidal ideation and behavior, with the intent of targeting these factors. First, we provide a theoretical framework that might help to overview some conceptual structure to this literature.

\section{Theory}

\subsection{Interpersonal Psychological Theory of Suicide}

Joiner's Interpersonal-Psychological Theory of Suicide (IPTS; Joiner, 2005; Van Orden et al., 2010) is the most well developed theory for suicide. This theory proposes that in order for a person to die by suicide they must have: (1) the desire to die (suicidal ideation) and (2) the

\footnotetext{
* Corresponding author.

E-mail address: gd342@drexel.edu (G. Diamond).
} 
acquired capability to enact the lethal means. Two internal states of mind drive the desire to die. Perceived Burdensomeness (PB) is characterized by feeling flawed or broken and a liability to loved ones (Van Orden et al., 2010). Feeling like a burden on others feeds thoughts that the individual would be better off dead. Thwarted belongingness (TB) speaks to the fundamental, existential need to belong (Baumeister and Leary, 1995). When this need is not met (i.e., thwarted) it results in a desire for death or passive suicide ideation (Van Orden et al., 2010). The construct of TB captures the impact of loneliness and the absence of perceived reciprocal, caring relationships that can buffer against suicidality. While the IPTS offers a powerful explanatory model, it is not conceptualized as a family phenomenon. The theoretical frame and the items on the assessment tool focus on general social relationships and connectedness to individuals or to a community (Joiner, 2005). Joiner first conceived of this model as a way to understand suicide in an adult population. For children and adolescents however, the family relationships serve as the primary context for defining ones sense of value and belongingness.

For this reason we have turned to attachment theory to help explain some of the psychological challenges conceptualized by the IPTS model more squarely in the context of family relationships.

\subsection{Attachment theory}

Attachment theory's central premise is that children have a basic evolutionary instinct to seek out parents for care and protection. Decades of research on attachment have shown that children who experience their caregivers as accurately attuned to their emotions and sensitively responsive to their needs, come to develop secure attachment bonds. Repeated positive experiences with caregivers over time enable children to form an "internal working model" of self and other. Securely attached children develop a relational expectation that their caregivers are supportive, caring, and responsive. This expectation fosters a model of themselves as loveable and worthy of care. Secure attachment is linked to positive physical and mental health outcomes in childhood and across the life span (Kobak et al., 2007; Sroufe, 2005).

Although peers take on significant relevance in adolescence, continued attachment to parents or caregivers remains critical to healthy adolescent development (Kobak et al., 2006). Secure attachment in adolescence is marked by confident expectations in a caregiver's availability to provide support, protection and guidance. During adolescence, sensitive parenting is more often characterized by verbal and conversational markers, such as collaborative communication, parental validation, and open discussion. These collaborative relational and conversational dynamics between parents and teens help to promote adolescent perspective taking, emotion regulation, and development of problem-solving skills. These conversations also improve adolescents mentalization; the capacity to reflect on one's emotions and the thoughts and feelings of others (Asen \& Fonagy, 2012). Furthermore, these dynamics provide adolescents with the foundation for negotiating autonomy and emerging adulthood (Kobak et al., 1993; Kobak et al., 2006; Steinberg, 1990).

In contrast, insecure attachment forms when children experience insensitive caregiving (parental rejection, withdrawal, intrusiveness). Children then internalize models of caregivers as being unavailable, misattuned, or, in the worst cases, frightening. They also tend to develop models of themselves as undeserving, unlovable, or not needing/ wanting care. Adolescents with a history of insecure attachment tend to view their parents as unsafe, untrustworthy, unreliable, and themselves as unworthy of love and comfort. These insecure attachment environments lead to pessimism, low self-esteem, and hopelessness. Ultimately, this makes adolescents more vulnerable to problems like depression, emotional dysregulation, and involvement with negative peers (Dykas et al., 2008; Kim et al., 2014; Lee \& Hankin, 2009; Van Durme et al., 2015). For a teen trying to coping with difficult emotions or experiences, the ability to go to a parent or another highly trusted adult for comfort, direction, and protection can be life-saving. Unfortunately, adolescents lacking a secure base are less likely to turn to their parents for help. In fact, for parent-teen dyads marked by insecure attachment dynamics (anxiety, avoidance, detachment), going to parents in times of distress may result in additional discomfort, negative emotion and conflict, potentially exacerbating psychological risk. Unable to self sooth or seek support, many distressed teens turn to suicidal thoughts or self-harm as a means to cope with difficult emotions, stressors, and experiences (Belsky \& Pluess, 2009; Cummings et al., 2002).

Attachment theory then provides a transactional model of adolescent development and psychopathology. Appreciating the role of biology and temperament, a transactional model assumes that early experience of relationships impact the development of one's internal psychological perspective on the trustworthiness of others, and the worth of self. The child/adolescent then begins to behave in ways that allow them to meet their needs or cope with unmet needs. Parents then respond in ways that promote growth, or further reinforce negative perceptions and feelings. Although attachment theory (and developmental theory in general) hold parents most responsible for determining the quality of parent-child relationships, these links are reciprocal. The child's behavior similarly impacts how the parent feel about the child, which in turn impacts the parent's behavioral response toward the child. This is especially true if parents have their own unmet attachment needs negatively informing their parenting style. Furthermore, interactions between co-parents also reinforce positive or negative views of self and other (for parents and children). In this way, attachment theory, and family systems frameworks, view family relationships as a constant transactional experience of interactions "between" people and internal psychological reactions "within" people.

If we assume these transactions are malleable, this transactional perspective bodes well for intervention. Interventions have the potential to interrupt the reinforcement of this negative transactional cycle and can reset families on the course of reestablishing or strengthening the secure base of the family environment. Change can start in different domains. We can give an adolescent medication to help regulate their biology. We can teach a child coping skills to help them in interpersonal relationships. Changes in either of these domains might help alter the interactional cycle from reinforcing negative behavior. From an attachment framework however, improving parenting behavior may be a key entry point for interrupting these deleterious system dynamics. The parents set the tone in family life. They either promote or derail the secure base. Even in the face of a child with several physical or psychological challenges, how parents respond to these challenges can greatly determine the degree to which the child remains on or falls off the appropriate developmental pathway. Given the potent entry point of parenting as a planned intervention strategy for youth at risk for suicide, we review next the research on parenting practices and general family environments that have been associated with youth suicide risk. We then look to see how family based interventions target these malleable factors.

\section{Family factors related to adolescent suicidal ideation and behavior}

\subsection{Parenting}

Parenting makes up an important dimension of family process that contributes to establishing a secure parent-child relationship. Three parenting domains have receiving the most attention in the suicide research literature. These include parenting style, parenting practices and parental involvement. These domains likely have similar qualities and indicators, but they have been used distinctly in the research literature.

\subsubsection{Parenting style}

Parenting style refers to general approach or theoretical (usually 
implicit) stance that guides parenting. Baumrind's model from 1971 is among the most frequently studied conceptualizations of parenting style (Baumrind, 1971). This model identified three parenting styles based on different constellations of warmth and structure (Steinberg, 1990). Authoritarian parenting consists of high control, low warmth, and harsh criticism. These parents tend to make rules and enforce consequences with little regard for a child's opinion. They use punishment instead of discipline and prioritize obedience over collaboration. Youth with authoritarian parents may be at elevated risk for developing lower selfesteem problems, because their opinions are not valued by their parents, and they tend to have more anger toward authority. Permissive parenting consisting of low control and high warmth. These parents rarely provide consequences for negative child behavior and if they do, it is often inconsistent. Youth in these families tend to struggle academically, exhibit more behavioral problems, and may lack appreciation for authority and rules. They often have low self-esteem and may be more vulnerable to depression. . Authoritative parents are high on both warmth and structure. They have rules and use consequences, but they also listen to their children and take their opinions into account. They validate their children's feelings, while also clarifying structures and rules in place within the family system. They tend to use positive discipline strategies like praise and reward to reinforce good behavior. Children raised by authoritative parents tend to be happy and successful.

Unfortunately, this rich and empirically supported system of characterizing parenting styles has received limited research with suicidal youth. Existing research suggests that parenting style may be associated with youth suicide risk and behaviors. In a study conducted in Hong Kong with 120 student participants, a significant correlation was found between perceived authoritarian parenting and suicide ideation, while a positive family climate was found to buffer this correlation (Lai \& McBride-Chang, 2001). In a survey conducted in Germany, authoritative parenting style was found to be a protective factor against youth's suicide attempts, while rejecting or neglecting parenting style was found to be a predictor of suicide behaviors (Donath, Graessel, Baier, et al. 2014). While not specifically defined as authoritarian, parenting styles such as scolding or physical punishment were associated with higher risk of suicidal behaviors among Chinese adolescents (Liu, Sun \& Yang, 2008). In a study exploring the relationship between parenting style and suicidal ideation, adolescents that ranked their parents as affectionlesscontrol on the Parental Bonding Instrument (PBI) had elevated levels of suicide thoughts, deliberate self-harm and depression compared to youth who ranked parents lower on this negative factors (Martin \& Waite, 1994).

\subsubsection{Parenting practices}

While parenting styles represent broader patterns of parenting, parenting practices represent actual parental behaviors. Even though much of the literature on parenting practices is narrowly focused behavioral management, a broaderfocus on care and control is also icnluded. On the care dimension, we will review research on validation vs invalidation, and parental criticism and warmth vs hostility. Findings on parenting practices and suicidal youth support the notion that parental engagement in behaviors characterized by support, care, validation and warmth toward their child buffers against suicidal ideation and suicide attempts and reduces self-harm behaviors. Typically, studies have explored parenting practices as mediating effects on suicide attempt, ideation and completion outcomes.

Beginning with the classic definition of parental practices, encompassing warmth versus control, Wong, De Man \& Leung (2002) found that low maternal and paternal warmth was associated with higher levels of suicidal ideation among Chinese students, while maternal and paternal control were not associated with suicide ideation. They also found that low maternal warmth, but not paternal warmth, was associated with increased youth suicide ideation. In another study on parental care vs control, using the PBI (Parental Bonding Instrument), suicidal behavior was linearly associated with parental conflict and low maternal and paternal care. Suicidal behavior was also associated with both high and low maternal and paternal control, but was lower in those with moderate parental control (Toumbourou \& Gregg, 2002). Furthermore, Lai \& McBride-Chang (2001) found a significant positive correlation between suicide ideation among Hong Kong students and low parental warmth, high maternal control, and negative parental practices in general.

Low parental emotional support, which can also be conceptualized as a lack of caring behaviors exhibited by parents, was found to predict a history of recent suicidal thoughts and also predicted history of suicide attempt among youth (Tomori, Kienhorst, De Wilde \& Van Den Bout, 2001). In a study exploring the mediating role of parental support on stress and suicidal ideation in adolescents, parental support was operationalized with a number of support subscales: 6 emotional support subscales, 4 academic support subscales and 4 financial support subscales. Parental support in general and each of the support subscales were significnatly correlated with decreased suicidal ideation. Furthermore, parental support was found to be a buffer in the relationship between life stress and suicidal ideation among adolescents (Kang et al., 2017). A study in rural Iowa found that adolescent distress mediated the relationship between paternal warmth and suicidality. In addition, maternal warmth was associated directly with adolescent suicidality (Cannor \& Reuter, 2006). Saffer and Klonsky (2014) found that lower parental care differentiated between adolescents with and without a history of suicide attempts.

Another aspect of parenting practices is parental criticism and parental dissatisfaction, which can be experienced by youth as hostility from the parent. In a study conducted in Hong Kong, parents' dissatisfaction with their youth was measured as the difference between adolescents reported "real" and "ideal" child to parent. A significant correlation was found between parent's dissatisfaction with academic performance and youth suicidal ideation and adolescent depression mediated this relationship (Lee, Wong, Chow \& McBride-Chang, 2006). In a study with families of adolescents hospitalized following a suicide attempt, parents were found to be twice as emotionally invalidating compared to those in a psychiatric control group (Aiken, Wagner \& Benjamin Hinnant, 2019).

Fewer studies have examined links between parenting practices and self-harm behaviors. In a study conducted in a laboratory setting, authors did not find an association between parental validation and support and self-injury behavior in adolescents. These findings may be explained by the fact that parents may have been more motivated to control their emotions in a lab setting, and the coding system used to code the relationship may not have been sensitive enough (Crowell et al., 2013). In another study, self-harming adolescents perceived their mothers as less caring and more controlling over the course of 16 years of their life (Diamond, Didner, Waniel \& Priel, 2005). Additional studies are needed to clarify links between parenting behaviors and self-harm.

\subsubsection{Parental involvement}

Another dimension of parenting that has received some attention is parental involvement in youth's lives. Parental involvement has consistently served as a protective factor against suicidal ideation and behaviors in adolescents. Flouri and Buchanan. (2002) found that parental involvement had a protective role in adolescents' suicidality, while lower parental involvement was associated with increased likelihood of suicide attempts (Flouri et al., 2002). In another study, adolescent perceived levels of parental involvement and support were a strong predictor of reduced suicide risk (Randel, Wang, Herting \& Eggert, 2006a). Wang et al. (2018) found that student's perception of parental involvement in their education was negatively associated with mental health difficulties and suicidal thoughts and behaviors. Borowsky, Ireland \& Resnick (2001) found that high parental expectations for their child's school achievement was a protective factor against suicide attempts in boys and parental presence at key times during the day was a protective factor for girls. 
Parental monitoring has been consistently examined in the conduct disorder research literature (Racz \& McMahon, 2011), but limited research has focused on monitoring and youth at risk for suicide. King et al. (2001) found that low parental monitoring was significantly associated with suicidal ideation and/or attempt, even after adjusting for the presence of youth's mood or disruptive disorder. However, in another study, parental monitoring was not a significant predictor for suicide ideation for both females and males (Perkins \& Hartless, 2002).

\section{General family environment}

In addition to the family factors described above, much research has also focused on general family environment. Next, we overview findings from this line of research.

\subsection{Family connectedness}

A lack of family connectedness has been consistently negatively associated with suicidal ideation and behavior in adolescents. Family connectedness is defined in many ways throughout the literature, but can be broadly operationalized as one's subjective perception of closeness and connection within family relationships (e.g., feelings of trust, care, belonging, and support; Whitlock, Wyman \& Moore, 2014). Due to the range in definition and measurement of this construct, we first present research that explicitly examined variables labeled as "family connectedness." Following this, we describe more general findings regarding family cohesion and support in association with suicidality. While family support and cohesion share overlapping features with connectedness, enough studies conceptualize these variables distinctly, warranting unique consideration of the links between these constructs and youth suicidality.

In a large, nationally representative sample, family connectedness was measured by items assessing perceived closeness to parent(s), perceived caring by parent(s), satisfaction with parental relationships, and feeling loved and wanted by family members (Borowsky, Ireland \& Resnick, 2001). Results revealed family connectedness was protective against suicide attempts among Black, Hispanic and White youth. In another study, family connectedness was a stronger buffer against suicidal ideation and behavior compared to connectedness to peers, school and other adults (Kaminski et al., 2010). In a longitudinal study, teens who felt more connected to their parents were significantly less likely to die by suicide (Kidd et al., 2006). This study also found parental support can be bolstered by positive school relations in protecting at risk boys against suicide. In a sample of Latinx students, odds of suicidal ideation were 2.3-8 times higher among students who perceived low levels of connectedness with their families (Garcia et al., 2008). In data from the National Comorbidity study, family cohesion showed a strong association with suicide outcomes across Latina and white girls, with some inconsistent findings for White males (Rapp et al., 2017).

Among sexual minority youth, a group at higher risk for suicide compared to their heterosexual counterparts, connectedness to parents was also associated with lower suicidal thoughts and fewer attempts (Eisenberg \& Resnick, 2006). Further, family connectedness was found to be the strongest of four protective factors in buffering against suicide risk among youth who experienced sexual abuse (Eisenberg et al., 2007). Together, these studies underscore the unique potential for family connectedness to buffer against suicidal ideation, behavior, and death by suicide among diverse youth, over and above other social relationships.

\subsection{Family cohesion}

Family cohesion is defined as the degree of commitment, emotional bond, and support that family members provide one another (Olson, Russell, \& Sprenkle, 1979). Like family connectedness, studies have found that family cohesion is negatively correlated with adolescent suicidality. Several international studies replicate findings that higher family cohesion is associated with lower levels of suicidal ideation and behavior among adolescents (Lee et al., 2006; Madu \& Matla, 2004; Liu, Sun \& Yang, 2008). In a sample of Latina adolescents in the U.S., suicide attempters were more likely to come from "loose knit" families, defined as those low in cohesion and high in conflict, compared to nonattempters (Peña et al., 2011). Within clinical samples, family cohesion has also been identified as a strong correlate of suicidal behavior. For instance, in a study comparing self-injuring to non-self-injuring youth, level of family cohesiveness differentiated these groups, with self-injurers evidencing lower levels of cohesion (Crowell et al., 2013).

Family cohesion has also been examined as a moderator and mediator for suicide risk among youth with depression and anxiety. For instance, depressed youth with lower levels of family cohesion report higher suicidal ideation compared to those with more cohesion (Au et al., 2009). The relationship between anxiety and suicidal ideation was also found to be stronger among adolescents reporting lower levels of family support (Machell et al., 2016). Family cohesion was found to mediate the relationship between social anxiety and suicidal behavior in non-Hispanic White female teens (Rapp et al., 2017). Thus, family cohesion appears to mitigate risk of suicidality among youth with other risk factors. In addition, mediation models suggest cohesion may be an important mechanism for understanding how suicidal ideation evolves among anxious youth.

\subsection{Family support and warmth}

Family support, defined by adolescent's perceptions that their family is valuable and can be relied on, has also been linked to adolescent suicidal ideation and behavior. In one recent study, family support was associated with reduced likelihood of having attempted suicide in a large sample of adolescents ages 12-18 (Zimmerman, 2013). In another sample evaluating multiple family factors, family support emerged as predictor of adolescent suicidal ideation and behavior. Within the same study, parental monitoring, parental addiction, parental education and family structure did not significantly predict suicidality (Perkins \& Hartless, 2002). In addition, satisfaction with family support was among the strongest predictors of youth suicide risk behaviors in a study of potential high school drop outs (Randell, Wang, Herting \& Eggert, 2006a). Another study found low levels of family warmth among suicide ideators compared to non-ideators (Lai \& McBride-Chang, 2001). A sample of youth who attempted to poison themselves perceived their mothers as less caring, compared to non-self-harming counterparts (Diamond, Didner, Waniel \& Priel, 2005). Maternal warmth, observed in an interaction task, has also been related to reduced youth suicidality (Connor \& Rueter, 2006).

Some evidence suggests that the strength of the link between family support and suicidality may differ by gender. In one study, family support buffered against suicidality for girls but not boys (Kerr et al., 2006). Similar to findings on family connectedness, research finds that family support is a stronger buffer against suicide risk than friend support (Cheng \& Chan, 2007). This study also found a strong relationship between stress and attraction toward death, highlighting that family and peer support accounted for $33 \%$ of the variance within this relationship. These findings underscore the potency of family support in reducing risk of suicidality among adolescents.

\subsection{Family conflict}

Conflict and relational problems within families may be the most studied family factor in its association to suicidal ideation and behavior among youth. One study found that relationship problems, particularly with parents, were the most common antecedent of youth death by suicide (Holland et al., 2017). Relational conflict within families has also been identified as a common trigger for suicide attempts, particularly among girls. Indeed, more than $50 \%$ of suicide attempters report that an 
interpersonal conflict triggered their attempt (Dieserud, Gerhardsen, Van den Weghe \& Corgett, 2010; Chérif et al., 2012). A study conducted in Hong Kong found that both distressed relationships and serious interpersonal conflicts within the family were correlated with suicidal ideation (Chan et al., 2009). Other work has also suggested that family climates characterized by conflict are associated with increased likelihood of suicidal ideation (Lai \& McBride-Chang, 2001). Adolescents who engaged in self-inflicted injury were found to be more likely than their matched controls to have mothers who escalate conflict during a clinical observation task (Crowell et al., 2013). Higher levels of family conflict and more frequent use of maladaptive conflict resolution tactics have also been associated with suicidal behavior among youth across cultures (Toumbourou \& Bregg, 2002; Liu, Sun \& Yang, 2008; Flouri \& Buchanan, 2002; Tang et al., 2009). In a recent study, family conflict involving factors such as fighting, criticism, competitiveness and anger within a family - was associated with a higher likelihood of suicide ideation and non-suicidal self-injury among children. Low parental monitoring - the extent to which children were "tracked and supervised by their parents" - was linked with suicidal ideation, suicide attempts and self-injury (DeVille et al., 2020).

Some research suggests that adolescent and parent's views on family conflict may differentially predict risk. That is, youth perception of family conflict has been associated with suicidal ideation, but parental report of conflict did not significantly relate to ideation (Goldstein et al., 2009). Similarly, studies have examined whether conflict uniquely predicts severity of suicide risk. The accumulation of evidence suggests that family conflict and relationship problems predict suicidality across the spectrum of risk, from ideation to behavior (Madu \& Matla, 2004). However, some evidence indicates that across a number of risk factors, family conflict was associated with the highest level of suicide risk categorization (Randell et al., 2006a). In a large sample of French adolescents, negative family relationships were significantly associated with four levels of suicide risk, with odds ratios increasing according to risk severity grade (Consoli et al., 2013).

\subsection{Family violence}

Youth who have witnessed or experienced family violence, maltreatment or abuse are at increased risk for suicide (Randell et al., 2006b). In particular, a history of physical abuse within the family has been found to significantly predict suicidal ideation (Wan \& Leung, 2010). In a large, nationally representative sample in the U.S. (Add Health study), experiencing sexual abuse perpetrated by a family member or caregiver increased the odds of suicide attempt by $92 \%$, compared to odds for those not exposed to this form of violence (Haynie, Petts, Maimon \& Piquero, 2009).

In addition, cumulative experiences of trauma, inclusive of family violence exposure, have been related to increased likelihood of suicidal behavior (Greger, Myhre, Lydersen \& Jozefiak, 2015; Cluver et al., 2015). Studies have not found evidence that developmental timing of exposure to maltreatment impacts suicidal ideation, rather findings emphasize that exposure to child maltreatment is strongly predictive of suicide risk in adolescence, regardless of when this occurs in one's developmental trajectory (Gomez et al., 2017).

\subsection{Family stress}

Stressful and adverse events occurring within the family have been associated with adolescent suicidality. In particular, cumulative experience of negative life events within the family is associated with higher risk for suicide among youth who are at risk for dropping out of school (Randell et al., 2006a). Another study found that youth who have bipolar disorder and suicidal ideation were more likely to have experienced the following adverse family events, relative to their counterparts without ideation: serious illness or injury of a family member, death of a family member, increase absence of a parent at home, trouble with a sibling, and increased arguments with parents (Goldstein et al., 2009). In this study, suicidal youth also reported more cumulative stressful life events. In a large sample of Chinese adolescents, findings suggested that social problems of family members independently predicted suicide attempt history, controlling for demographic and lifestyle variables (Xing et al., 2010). Together, these results highlight the relationship between family stress and suicidality among youth who are considered at risk and clinical populations.

Studies have also identified pathways from family stress to adolescent suicidal ideation. One study of youth found that family economic stress predicted parental depression, which in turn predicted adolescent suicidal ideation. The association between parental depression and youth suicidal ideation was mediated by parental hostile behaviors and physical abuse (Yoder \& Hoyt, 2005). Further investigation of pathways from family stress to suicidality is needed.

\section{Family factors in adolescent suicide treatment programs}

The research reviewed above paints a consistent picture. Youth who live in more supportive, well structured, emotionally validating family environments seem less likely to be at risk for suicide. In contrast, adolescents who live in families characterized by high conflict, parental control, and harsh criticism are more likely to experience problems related to suicidality. Integrating an IPTS lens, it is possible that these negative family processes promote a sense of thwarted belongingness or perceived burdensomeness. From an attachment perspective, these negative family dynamics and interactional patterns reduce the possibility that teens can use parents as a secure base for navigating the frequently turbulent waters of adolescent development. Fortunately, these family processes may be malleable and open to improvement through psychosocial treatment (see Steele \& Steele, 2017 for an overview of attachment based psychotherapies). It is not surprising that nearly all well-developed, empirically supported treatments for youth at risk for suicide include a family component in the treatment protocol (Diamond, Asarnow, \& Hughes, 2017). How and to what degree these treatments focus on family processes varies greatly.

We review these interventions, highlighting how they include families (usually parents) in the approach. The treatment effectiveness of these interventions has been well reviewed in several other papers (Brent et al., 2013; Glenn et al., 2015; Ougrin et al., 2015). Here we focus on the structure and dose of family involvement as well as secondary research on family factors as moderators, mediators and treatment outcomes, where such data exists. In some of these models, family process is the primary target; in other treatments, family process can be considered a secondary intervention target.

\subsection{Family involvement in youth suicide interventions}

For the purpose of this paper, we conceptualize family involvement in treatment as falling along a continuum ranging from individual treatment that includes a family component to family therapy treatments that focus explicitly on the quality of intra-familial relationships (see Table 1). In between are individual and family treatments that vary in how they incorporate families in the treatment process, the specific family processes targeted, and whether improvements in family functioning are viewed as key mechanisms of change or as a secondary process that enhance treatment. This conceptual framework will provide a heuristic tool for conceptualizing the type and purpose of family involvement across diverse treatments.

\subsection{TASA}

The Treatment of Adolescent Suicide Attempters (TASA) study emerged from a programmatic line of research led by several prominent adolescent depression and suicide treatment researchers. This work began focused on adolescent depression (TADS), then moved to 
Table 1

Family component in various intervention models for suicidal youth.

\begin{tabular}{|c|c|c|c|c|}
\hline $\begin{array}{l}\text { Intervention } \\
\text { models }\end{array}$ & Primary intervention of the model & $\begin{array}{l}\text { The family role in } \\
\text { the treatment }\end{array}$ & Type of family modality & Primary target for the family intervention \\
\hline $\begin{array}{l}\mathrm{CBT}+\text { medication } \\
\text { (TASA) }\end{array}$ & $\begin{array}{l}\text { CBT-SP cognitive behavioral for suicide } \\
\text { prevention change }+ \text { medication }\end{array}$ & Secondary process & $\begin{array}{l}\text { Single family psycho- } \\
\text { education program }\end{array}$ & $\begin{array}{l}\text { Chain analysis, safety planning and coping } \\
\text { strategies with some attention to family process }\end{array}$ \\
\hline I-CBT & $\begin{array}{l}\text { S-O-R-C model (cognitive behavior model for } \\
\text { treating and understanding problem behavior) }\end{array}$ & Secondary process & $\begin{array}{l}\text { Single family psycho- } \\
\text { education }+ \text { conjoint } \\
\text { family sessions }\end{array}$ & $\begin{array}{l}\text { Motivational interviewing, strategies for treatment } \\
\text { engagement, parental monitoring. In family session } \\
\text { - applying learned skills to address key problems }\end{array}$ \\
\hline SAFETY & $\begin{array}{l}\text { Social-ecological CBT for behavioral change, } \\
\text { promoting protective and decreasing risk } \\
\text { factors }\end{array}$ & Secondary process & $\begin{array}{l}\text { Single family psycho- } \\
\text { education }+ \text { family } \\
\text { therapy sessions }\end{array}$ & $\begin{array}{l}\text { Appreciation for one another, skills learning, joint } \\
\text { problem solving }\end{array}$ \\
\hline DBT & Improving adolescent emotion regulation & Secondary process & $\begin{array}{l}\text { Multifamily psycho- } \\
\text { education group }+ \text { family } \\
\text { therapy sessions }\end{array}$ & Parental self-regulation and empathic parenting \\
\hline $\begin{array}{l}\text { Mentalization } \\
\text { therapy }\end{array}$ & $\begin{array}{l}\text { Psychodynamic therapy-conversation and } \\
\text { exploration, promoting mentalization about } \\
\text { oneself and other }\end{array}$ & Secondary process & $\begin{array}{l}\text { Individual and Family } \\
\text { therapy session }\end{array}$ & $\begin{array}{l}\text { Exploration of feelings and needs that drive } \\
\text { behavioral problems }\end{array}$ \\
\hline $\begin{array}{l}\text { Attachment based } \\
\text { family therapy }\end{array}$ & $\begin{array}{l}\text { Interpersonal process-oriented family therapy, } \\
\text { aiming to identify and work through ruptures in } \\
\text { the parent adolescent relationship }\end{array}$ & $\begin{array}{l}\text { Primary target and } \\
\text { mechanism of } \\
\text { change. }\end{array}$ & Family therapy sessions & $\begin{array}{l}\text { In session, corrective attachment experience that } \\
\text { work though family ruptureld new interpersonal } \\
\text { skills. }\end{array}$ \\
\hline
\end{tabular}

treatment resistant depression (TORDIA) and then moved to youth suicide (TASA). These studies were primarily CBT, medication or combination studies. Investigators found they had to provide support, if not intervention, with parents, either for engagement and cooperation or to actually target processes that were contributing to the teen's depression.

In the TADS study, investigators felt the need to address parent engagement and negative family processes believed to be associated with depression. The manual developed for the TADS study was carried forward into TORDIA and TASA (Wells \& Albano, 2005). The manual offered up to six family sessions in the acute phase, with the allowance of family "check-ins" (5-15 min) at weekly sessions, and three family sessions during the 3 months continuation phase (Brent, Emslie, et al., 2009). Parent involvement was required in at least 3 sessions. These family sessions focused on chain analysis, safety planning, psychoeducation, and reasons for living and hope. After the first three sessions, adolescents were able to choose if they wanted family sessions. It was reported that $50-75 \%$ of the families received at least safety planning, psychoeducation, a communication model and problem solving with the average number of these sessions being 5.67 ( $S D=3.89$, range 015 ). During the continuation phase, family sessions focused on new skill acquisition, relapse prevention, anticipating future crises, and disposition planning. These sessions also focused on family behavioral activation, family emotion regulation, family problem solving, family communication, and family cognitive restructuring (Stanley et al., 2009; Wells \& Heilbron, 2012). Main findings from the study are promising but call for more investigation, given the open trial study design (Brent, Greenhill, et al., 2009, Stanley et al., 2009, Vitiello et al., 2009).

TASA itself was a large multi-site, open trial, NIMH-funded study of depressed adolescents with a recent suicide attempt recruited from the emergency room. The primary goal was risk-reduction and relapse prevention accomplished by targeting cognitive and emotional dysregulation. The primary intervention model was Cognitive Behavioral Therapy for Suicide Prevention (CBT-SP) (Stanley et al., 2009). Treatment also incorporated elements from skills training, DBT, and parent training (Brent, Greenhill et al., 2009). The study was originally a randomized trial comparing medication to CBT intervention, but parents refused to accept medication only, so the project was converted to an open trial.

In addition to treatment outcome papers, this productive line of research has yielded many papers examining treatment moderators. For example, in the TORDIA study for treatment resistant adolescents family conflict significantly predicted greater risk for the occurrence of a suicidal adverse event, measured by new or worsening ideation, suicidal threat, or attempt during treatment. In TADS, family income (SES) moderated treatment outcome (Curry et al., 2006a, 2006b). Feeny et al. (2009) found in the TADS study that adolescents with mothers who reported less parent-child conflict were more likely to benefit from treatment than their counterparts. When family functioning moderated outcome, adolescents who endorsed more negative environments were more likely to benefit from fluoxetine. Similarly, when moderating effects were seen on cognitive behavioral therapy conditions, they were in the direction of being less effective among teens reporting poorer family environments. Unfortunately, there have been no family based moderator studies with the data from TASA, the only specific suicide intervention from this team of investigators.

\subsection{Integrated CBT (I-CBT)}

Integrated CBT (I-CBT) is a cognitive-behavioral family model that targets both suicidality and substance use disorders. This approach builds on CBTs and motivational interviewing for suicidal youth with cooccurring substance use (Donaldson et al., 2005; Esposito-Smythers et al., 2011). The model draws on a social cognitive learning theory, skills-based parent training, and family therapy sessions. It frames most problems through the S-O-R-C model, which views problem behavior as a combination of stimulus-organism-response-consequences. Family problems such as divorce or conflict are viewed through this lens, and cognitive behavioral skills are deployed to interrupt these behavioral sequences.

I-CBT is designed as a 12-month treatment, with a six-month acute phase, a three-month continuation phase, and a three-month maintenance phase with treatment dose fading over time - from weekly to monthly. In the first 4 months of treatment, adolescents and parents mostly meet alone with their respective therapists, learning cognitive and behavioral skills to help address the adolescent's suicidal feelings and substance use. The parent sessions focus on motivational interviewing strategies to enhance parental engagement. Therapists also focus on parental monitoring, parental cognitive restructuring, parental emotion regulation, parental problem-solving, and positive attending to adolescent's needs. These psycho-education sessions are focused on teaching skills and then helping parents apply them to the specific problems the family is experiencing. After these skills have been learned, there are conjoint family therapy sessions to practice applying and using skills to address key problems. To our knowledge, no existing published studies have examined family moderators, mediators or outcomes.

\subsection{SAFETY program}

The SAFETY program is a family based social-ecological cognitivebehavioral model of behavior change (Asarnow et al., 2015, 2017; Henggeler et al., 2002). The treatment views individual, family, socialecological, and interactional processes as critical change targets of 
treatment (Asarnow \& Miranda, 2014). Treatment targets the suicidal youth's feelings of burdensomeness and disconnectedness (Czyz et al., 2012; Joiner, 2005; King et al., 2010) by promoting social supports and connection to one's social network (family, peer, school, community).

The SAFETY program provides a highly intensive treatment over a 12-week period, with session dose varying from one to multiple sessions a week. Therapists are available for phone coaching $24 \mathrm{~h}$ a day, every day. Home visits are used as needed with at least one session in the home, school or community. Two therapists are assigned to each case: one for the youth and one for the parents/family/community. The first part of each session involves the individual component (each therapist works alone with youth/parents) and the second part of the session focuses on the family component with a standard agenda (appreciation for one another, followed by parents and youth sharing what they learned in the individual part of the session, working together on a specific problem solving area and finally assigning a "family practice" assignment). In a small study exploring treatment moderators, investigators found that the treatment, unexpectedly reduced parental depression, a known risk factor for youth. As this was an exploratory and unexpected finding, no analyses were conducted to see if reduction in this factor contributed to adolescent symptom reduction (Babeva et al., 2020).

\subsection{Dialectical behavior therapy (DBT)}

Dialectical behavior therapy, originally developed as a treatment for chronically suicidal adults (Linehan, 1993a, 1993b), has also been adapted for use with self-harming adolescents who exhibit borderline personality features (Miller et al., 1997; Rathus \& Miller, 2002). DBT specifically targets behaviors and emotions that are antecedents to suicidal behavior. The adult model relies on a "consultation-to-the-patient" approach in which therapists advise patients on how to effectively change in their environments. For adolescents, therapists must intervene more directly with the family where patients are often less able to act for themselves (Linehan, 1993a).

The adaptation of DBT for adolescents then can be viewed as incorporating a family systems perspective within the DBT model (Miller et al., 2002; Miller et al., 2007; Woodberry et al., 2002). Based on a biosocial model, DBT posits that dispositional, suicidal adolescents are emotionally sensitive and reactive and have a slower return to baseline once emotionally activated. When these individuals live in families with high levels of invalidation, suicidal behavior and urges are activated. Therefore, the family intervention aims to increase parental validation of the adolescent (Miller et al., 2002; Woodberry et al., 2002).

DBT for adolescents is an intensive outpatient treatment program that involves a minimum of $3 \mathrm{~h}$ per week. This includes one individual hour and $2 \mathrm{~h}$ of multi-family skills training, with therapists on-call around the clock for youth and parent phone coaching. The intervention, however, goes beyond just education, encouraging individual family members to apply newly-learned skills to relevant family issues (Miller et al., 2002). Key skills emphasized in these groups include: mindfulness, dialectics, validation, distress tolerance, emotion regulation, and interpersonal effectiveness. A frequent comment from parents in skills group is "I wish I had learned these skills when I was my child's age" (Asarnow, personal communication, 2014).

Family work focuses on three domains in particular. First, adolescents learn chain analysis in order to understand the causes and antecedents of self-harm behavior. In terms of family triggers, this analysis often focuses on family conflicts and/or the adolescent feeling invalidated. Second, family sessions can address parent or family barriers to the adolescent's treatment adherence (e.g., transportation). Finally, family sessions are used for practicing new skills. It should be noted, however, that adolescent DBT uses a limited number of "family" sessions; multi-family skills group and phone coaching are the major modalities used with families.

A key family process target is DBT is parental validation. As reviewed above, this is a well-established protective factor against a number of mental health forms of distress. According Linehan's biosocial theory (1993), self-harm partially emerges from a severe and persistent difficulty regulating one's emotions. An invalidating parent can promote this dysregulation. The invalidating environment is characterized by inconsistent, inappropriate or and insensitive emotional responsiveness. The intervention primarily uses one session of psychoeducation to teach parenting skills. Using a sophisticated coding scheme for family interactions, investigators found a strong association between parental validation, invalidation and adolescent self-harm. There were no significant associations observed between parental validation, invalidation, and adolescent suicidal ideation. Observed levels of parental validation and invalidation were not changed during the six-month course of psychotherapy (Adrian et al., 2018). Investigators are now exploring a more extended psychoeducation program focused on validation (Adrian, personal communication).

\subsection{Mentalization therapy}

Mentalization therapy is an individual psychodynamic therapy that is augmented by a family therapy component (Rossouw \& Fonagy, 2012). The intervention relies on attachment theory to understand how families can promote positive or negative psychological health in children. The model assumes that parent's ability to mentalize, affects how children start to think about themselves and others. Mentalization is the capacity for sensitivity to others internal psychological states and is a skill that develops in the context of a secure attachment relationship (Fonagy \& Target, 2000). The assumption is that parents who can mentalize (understand and appreciate their child's inner emotional experience and needs) help children learn how to do this themselves. Thus, they learn how to recognize and express their own emotional needs more directly. Maladaptive behavior patterns and/or escalating family conflicts partially result from a failure in metalization. When parents misinterpret children's emotional needs, children feel ignored, criticized or invisible. This invalidation can prohibit children from recognizing their own hurt or vulnerable feelings.

Treatment structure follows a psychodynamic format of conversation and exploration.

Treatment aims to promote mentalization about oneself (become more aware of one's emotional needs, feelings and thoughts) and about others feelings and needs'. If parents and children have conflicts about school, the therapist encourages the parents to be curious about possible underlying feelings and needs that drive these behavior problems (e.g., fear of failure). Treatment lasts for one year, with the intention of weekly individual sessions and monthly family sessions. In the only RTCT with this model, patients only received on average 9 sessions total and nearly $1 / 3$ of the patients in the family treatment had no family session, because engagement was difficult. Still the experimental treatment performed better than treatment as usual on symptoms reduction. More impressively, compared to the control group, parents in the treatment group showed a slight but significant increase in recognition of emotions and the adolescents reported a significant decrease in attachment avoidance. Changes in both these scores were associated with reduction in self-harm, and there was support that these changes actually mediated improvements in symptoms.

\subsection{Attachment based family therapy (ABFT)}

Attachment based family therapy (Diamond et al., 2013) represents the end of the spectrum of family therapy interventions where improvement in family relationships is the primary mechanism of change. ABFT relies on developmental research that suggests the central task of adolescence is to remain appropriately close to parents while developing autonomy (Lerner \& Steinberg, 2009). Adolescents who feel close and comfortable with their parents are less likely to be involved with negative peers, use drugs, be depressed or do poorly in school (Kobak \& Herres, 2012). Treatment, therefore focuses on identifying and 
working through relational ruptures that have gotten in the way of adolescents appropriately trusting their parents.

Relational ruptures can result from traumas with a big " $\mathrm{T}$ " or little "t." Traumas with a big T refer to experiences with various forms of abuse, neglect or abandonment, which can be highly prevalent among adolescents at risk for suicide and/or struggling with self-harming behavior. Traumas with a little " $t$ " refer to chronic negative interpersonal and family processes, such as high control and low warmth, harsh criticism, or indifference in the family. Frequently in these families, adolescents have little freedom to express thoughts and feelings about these conditions. The absence of these conversations denies the adolescent validation for their feelings, help in understanding their feelings (mentalization), and the opportunity to repair the trust that has been damaged by these family processes or traumas. The therapy then provides a "attachment repair experiences" where adolescents begin to express vulnerable feelings and thoughts while the parents remain available and responsive.

To provide focus and structure to this interpersonal, process-oriented therapy, the treatment is delivered as a brief, weekly, 12 to 16-week program. Treatment is organized around five clinical tasks. The Relational Reframe Task (usually the first session) shifts the focus of the therapy away from behavioral management and onto improving the quality of parent and adolescent trust and safety. Then, the Alliance Building Task with the adolescent alone (typically two to three sessions) focuses on helping adolescent understand how attachment disappointments contribute to his or her feelings of depression and or suicide. Therapists then prepare the adolescent to discuss these ruptures directly with parents. Meanwhile, the therapist meets alone with the parents for the alliance building task with the parents ( 2 to 3 sessions). These sessions explore how current stressors and or their own intergenerational disappointments contributed to parenting. The therapist prepares the parents for up-coming conversations with their adolescents by teaching emotion coaching skills.

In the reattachment task ( 2 to 4 sessions) the therapist helps the adolescent express vulnerable and unarticulated thoughts and feelings. Parents respond with empathy, understanding, and validation, thus helping the adolescent improve emotional regulation and interpersonal problem-solving skills. The experience of having this new, productive conversation challenges internal attributions about self and other and elevates expectations of support and safety. The final task is focused on promoting autonomy. With the attachment relationship somewhat repaired, parents now serve as a secure base for solving day-to-day personal, family and social problems.

The ABFT research team has been dedicated to a programmatic agenda of process research that aims to understand the active mechanism of change that drives the effectiveness of the model (see Diamond et al., 2016, for a review). In our 2002 study (Diamond et al.) ABFT increased adolescent-reported family cohesion and perceived attachment on self-report measures. In our 2010 study, ABFT was even effective with the most severe youth presenting with comorbid anxiety and a history of multiple suicide attempts. ABFT also worked well with patients how had a history of sexual abuse (Diamond et al., 2012), a finding not supported in several CBT or CBT + medication studies (e.g., Barbe et al., 2004a, 2004b). In our 2019 study, ABFT was most effective for adolescents from traditionally underserved families and adolescents who engaged in less cooperative communication with their caregivers. Observational ratings of parent-adolescent communication were better prognostic indicators of treatment response than were self-reported indicators of global family functioning (Zisk et al., 2019).

Several studies have examined the relationships between treatment process and proximal or distal outcomes. For example, we found that strength of the parent-therapist alliance predicted parents' ability to use new more positive parenting practices (Feder \& Diamond, 2016). In another study, ABFT predicted a decrease in maternal psychological control and an increase in maternal psychological autonomy granting. An increase in autonomy granting was associated with increases in adolescents perceived parental care from pre- to mid-treatment and decreases in attachment treated anxiety and avoidance pre- to posttreatment. Decreases in adolescents' perceived parental control at mid-treatment was associated with reductions in adolescents' depressive symptoms at post treatment. Finally, in a new study by Winley et al., (under review), observational coding showed an increase in parent's use of validation during the core attachment task process in mid treatment. This increase was associated with decreases in adolescent depression from pre to post treatment.

\section{Discussion}

This paper reviewed the family processes that have been associated with youth suicide and how modern empirically supported interventions for this population incorporate these processes into to treatment. We have identified a variety of family factors that influence the likelihood and emergence of suicidal ideation and behavior among adolescents. In particular, parenting processes, family climate factors, and stressors occurring within the family context have all been found to be associated with adolescent suicidal ideation and behavior. While parenting processes vary in how they are operationalized, the key principle here is that when parents are consistent, reliable, warm, caring, involved, and validating of their child's emotional experiences, parenting can play a protective role against youth suicide. Conversely, parenting that is hostile, critical, inconsistent and overly controlling, has been consistently associated with elevated risk for suicide.

In addition to parenting quality, we have discussed general family environmental factors that can impact youth suicide risk. When an adolescent perceivestheir family as close, connected, and supportive, these youth seem to be less at risk for suicidal thoughts and behaviors. In contrast, high family conflict, low warmth, and high control have been associated with elevated risk for suicide. In addition, stressors occurring within the family landscape, including a number of adverse event experiences, can elevate risk for suicidality. Many studies across these domains also highlight the unique role that families play, over and above the role of peers and other social relationships. Thus, there is compelling evidence to suggest that parenting and the general family environment can serve as both a risk for, and buffer against, risk for youth suicide.

In order to further develop our understanding of the impact of family factors on adolescent suicide risk, additional research is needed in several key areas. First, most suicide studies approach family processes from a dyadic perspective (e.g., between a child and a parent). Yet, in families with two parental figures (mother/father, parent/grandparent) relational patterns are more complex. A patient might express feeling loved and comforted by one parent, but rejected and criticized by the other. How and if a positive relationship might buffer against a negative relationship is not well understood. Researchers might also look at more complete risk algorithms that improve the prediction of suicide. Do variations in suicide ideation and behavior reflect different family processes and structures? Do family profiles plus other risk factors help to build a more comprehensive prediction models model (Diamond, Herres, et al., 2017; Herres et al., 2017).

More research is also needed to understand what contribution they can make to the treatment of youth at risk for suicide. Ways in which family processes operate and change in treatments for adolescent suicide risk has received limited investigation. Even when studies do include intervention targeting family processes, they do not usually report improvement in family functioning as a treatment mediator or outcome. In addition, research that helps clinicians to more easily screen for and identify adolescent and family interactional profiles that are particularly high-risk clinically, would help clinicians target their interventions to the most needed processes. Type of intervention that would best target these processes (e.g., psychoeducation, family support group, individual meetings with parents, conjoint family sessions) would also need to be investigated. 
What are the implications for treatment? When clinically working with youth at risk for suicide, the family context is unavoidable. Consequently, most adolescent suicide interventions have developed a parent/family focused treatment that aim to reduce negative and increase positive family processes. How these family processes operate has received limited investigation. Most studies have looked at family processes as a moderator of treatment. The findings are mixed. Few studies have looked at family processes as an outcome of treatment. Family based treatment moderators have received surprisingly little investigation and family mediators even less. Still, all treatments have attempted to harness the potential of improving family relationships as a primary or secondary contribution to treatment outcome. More research is needed to understand how to improve family process and what contribution they can make to the treatment of youth at risk for suicide.

We are by no means suggesting that family factors are the only, or even the most important factor fueling youth suicide. In some families, family processes seem to directly contribute to youth suicidal thoughts and behavior (e.g., anger about a divorce or a parents' alcoholism). In other families relationships might be problematic, but not the direct cause of suicide risk. However, when youth experience stressors outside the home or internally (e.g. medical or mental health problems), how the family responds to these stressor can have a big impact on how the adolescent copes with these challenges. If parents provide a secure base, adolescents may be more likely to turn to parents for help and support. In this regard, we see family factors as both a risk or protective factor, and one that can be mobilized to help protect the adolescent against suicide.

\section{References}

Adrian, M., Berk, M. S., Korslund, K., Whitlock, K., McCauley, E., \& Linehan, M. (2018). Parental validation and invalidation predict adolescent self-harm. Professional Psychology: Research and Practice, 49(4), 274-281.

Aiken, C. S., Wagner, B. M., \& Benjamin Hinnant, J. (2019). Observed interactions in families of adolescent suicide attempters. Suicide \& Life-Threatening Behavior, 49(1), 104-119.

Asarnow, J. R., Berk, M., Hughes, J. L., \& Anderson, N. L. (2015). The SAFETY program: A treatment-development trial of a cognitive-behavioral family treatment for adolescent suicide attempters. Journal of Clinical Child \& Adolescent Psychology, 44 (1), 194-203.

Asarnow, J. R., Hughes, J. L., Babeva, K. N., \& Sugar, C. A. (2017). Cognitive-behavioral family treatment for suicide attempt prevention: A randomized controlled trial. Journal of the American Academy of Child and Adolescent Psychiatry, 56(6), 506-514.

Asarnow, J. R., \& Miranda, J. (2014). Improving care for depression and suicide risk in adolescents: Innovative strategies for bringing treatments to community settings. Annual Review of Clinical Psychology, 10, 275-303.

Asen, E., \& Fonagy, P. (2012). Mentalization-based therapeutic interventions for families. Journal of Family Therapy, 34(4), 347-370.

Au, A. C., Lau, S., \& Lee, M. T. (2009). Suicide ideation and depression: The moderation effects of family cohesion and social self-concept. Adolescence, 44(176), 851.

Babeva, K. N., Klomhaus, A. M., Sugar, C. A., Fitzpatrick, O., \& Asarnow, J. R. (2020), Adolescent suicide attempt prevention: Predictors of response to a cognitive-behavioral family and youth centered intervention. Suicide and Lifethreatening Behavior, 50(1), 56-71.

Barbe, R. P., Bridge, J., Birmaher, B., Kolko, D., \& Brent, D. A. (2004b). Suicidality and its relationship to treatment outcome in depressed adolescents. Suicide and Lifethreatening Behavior, 34(1), 44-55.

Barbe, R. P., Bridge, J. A., Birmaher, B., Kolko, D. J., \& Brent, D. A. (2004a). Lifetime history of sexual abuse, clinical presentation, and outcome in a clinical trial for adolescent depression. The Journal of Clinical Psychiatry, 65(1), 77-83.

Baumeister, R. F., \& Leary, M. R. (1995). The need to belong: desire for interpersonal attachments as a fundamental human motivation. Psychological Bulletin, 117(3), 497.

Baumrind, D. (1971). Current patterns of parental authority. Developmental psychology, 4 (1p2), 1.

Belsky, J., \& Pluess, M. (2009). Beyond diathesis stress: Differential susceptibility to environmental influences. Psychological Bulletin, 135(6), 885.

Borowsky, I. W., Ireland, M., \& Resnick, M. D. (2001). Adolescent suicide attempts: risks and protectors. Pediatrics, 107(3), 485-493.

Brent, D. A., Emslie, G. J., Clarke, G. N., Asarnow, J., Spirito, A., Ritz, L., Keller, M. B. (2009). Predictors of spontaneous and systematically assessed suicidal adverse events in the treatment of SSRI-resistant depression in adolescents (TORDIA) study. The American Journal of Psychiatry, 166(4), 418-426.

Brent, D. A., Greenhill, L. L., Compton, S., Emslie, G., Wells, K., Walkup, J. T. Turner, J. B. (2009). The Treatment of Adolescent Suicide Attempters study (TASA): Predictors of suicidal events in an open treatment trial. Journal of the American Academy of Child \& Adolescent Psychiatry, 48(10), 987-996.
Brent, D. A., McMakin, D. L., Kennard, B. D., Goldstein, T. R., Mayes, T. L., \& Douaihy, A. B. (2013). Protecting adolescents from self-harm: A critical review of intervention studies. Journal of the American Academy of Child \& Adolescent Psychiatry, 52(12), 1260-1271.

CDC. (2012). http://www.cdc.gov/violenceprevention/suicide/consequences.html.

Chan, W. S. C., Law, C. K., Liu, K. Y., Wong, P. W. C., Law, Y. W., \& Yip, P. S. F. (2009). Suicidality in Chinese adolescents in Hong Kong: the role of family and cultural influences. Social Psychiatry and Psychiatric Epidemiology, 44(4), 278-284.

Cheng, S. T., \& Chan, A. (2007). Multiple pathways from stress to suicidality and the protective effect of social support in Hong Kong adolescents. Suicide and Lifethreatening Behavior, 37(2), 187-196.

Chérif, L., Ayedi, H., Sahnoun, F., Walha, A., Moalla, Y., Rekik, N., \& Ghribi, F. (2012). Psychopathologie des tentatives de suicide chez les adolescents. Neuropsychiatrie de l'Enfance et de l'Adolescence, 60(6), 454-460.

Cluver, L., Orkin, M., Boyes, M. E., \& Sherr, L. (2015). Child and adolescent suicide attempts, suicidal behavior, and adverse childhood experiences in South Africa: A prospective study. Journal of Adolescent Health, 57(1), 52-59.

Connor, J. J., \& Rueter, M. A. (2006). Parent-child relationships as systems of support or risk for adolescent suicidality. Journal of Family Psychology, 20(1), 143-155.

Consoli, A., Peyre, H., Speranza, M., Hassler, C., Falissard, B., Touchette, E., ... RévahLévy, A. (2013). Suicidal behaviors in depressed adolescents: role of perceived relationships in the family. Child and Adolescent Psychiatry and Mental Health, 7(1), $1-12$.

Crowell, S. E., Baucom, B. R., McCauley, E., Potapova, N. V., Fitelson, M., Barth, H., Beauchaine, T. P. (2013). Mechanisms of contextual risk for adolescent self-injury: Invalidation and conflict escalation in mother-child interactions. Journal of Clinical Child \& Adolescent Psychology, 42(4), 467-480.

Cummings, E. M., Davies, P. T., \& Campbell, S. B. (2002). Developmental psychopathology and family process: Theory, research, and clinical implications. New York: Guilford Press.

Curry, J., Rohde, P., Simons, A., Silva, S., Vitiello, B., Kratochvil, C., ... TADS Team. (2006a). Predictors and moderators of acute outcome in the treatment for adolescents with depression study (TADS). Journal of the American Academy of Child \& Adolescent Psychiatry, 45(12), 1427-1439. https://doi.org/10.1097/01. chi.0000240838.78984.e2

Curry, J., Rohde, P., Simons, A., Silva, S., Vitiello, B., Kratochvil, C., ... March, J. (2006b). Predictors and moderators of acute outcome in the Treatment for Adolescents with Depression Study (TADS). Journal of the American Academy of Child and Adolescent Psychiatry, 45(12), 1427-1439.

Czyz, E. K., Liu, Z., \& King, C. A. (2012). Social connectedness and one-year trajectories among suicidal adolescents following psychiatric hospitalization. Journal of Clinical Child \& Adolescent Psychology, 41(2), 214-226.

DeVille, D. C., Whalen, D., Breslin, F. J., Morris, A. S., Khalsa, S. S., Paulus, M. P., \& Barch, D. M. (2020). Prevalence and family-related factors associated with suicidal ideation, suicide attempts, and self-injury in children aged 9 to 10 years. JAMA Network Open, 3(2), e1920956.

Diamond, G. M., Didner, H., Waniel, A., \& Priel, B. (2005). Perceived parental care and control among Israeli female adolescents presenting to emergency rooms after selfpoisoning. Adolescence, 40(158), 257.

Diamond, G., Herres, J., et al. (2017). Comprehensive screening for suicide risk in primary care. The American Journal of Preventive Medicine, 53(1), 48-54. https://doi. org/10.1016/j.amepre.2017.02.020

Diamond, G. S., Asarnow, J., \& Hughes, J. (2017). Optimizing family intervention in the treatment of suicidal youth. In D. A. Lamis, \& N. J. Kaslow (Eds.), Advancing the science of suicidal behavior: Understanding and intervention. Hauppauge, NY: Nova Science Publishers.

Diamond, G. S., Creed, T., Gillham, J., Gallop, R., \& Hamilton, J. L. (2012). Sexual trauma history does not moderate treatment outcome in Attachment-Based Family Therapy (ABFT) for adolescents with suicide ideation. Journal of Family Psychology, 26(4), 595-605.

Diamond, G. S., Diamond, G. M., \& Levy, S. A. (2013). Attachment-based family therapy for depressed adolescents. Washington, DC: American Psychological Association.

Dieserud, G., Gerhardsen, R. M., Van den Weghe, H., \& Corbett, K. (2010). Adolescent suicide attempts in Bærum, Norway, 1984-2006. Crisis.

Dimeff, L., \& Linehan, M. M. (2001). Dialectical behavior therapy in a nutshell. The California Psychologist, 34(3), 10-13.

Donaldson, D., Spirito, A., \& Esposito-Smythers, C. (2005). Treatment for adolescents following a suicide attempt: Results of a pilot trial. Journal of the American Academy of Child \& Adolescent Psychiatry, 44(2), 113-120.

Donath, C., Graessel, E., Baier, D., Bleich, S., \& Hillemacher, T. (2014). Is parenting style a predictor of suicide attempts in a representative sample of adolescents? BMC Pediatrics, 14(1), 1-13.

Dykas, M. J., Ziv, Y., \& Cassidy, J. (2008). Attachment and peer relations in adolescence. Attachment \& Human Development, 10(2), 123-141.

Eisenberg, M. E., Ackard, D. M., \& Resnick, M. D. (2007). Protective factors and suicide risk in adolescents with a history of sexual abuse. The Journal of Pediatrics, 151(5), $482-487$.

Eisenberg, M. E., \& Resnick, M. D. (2006). Suicidality among gay, lesbian and bisexual youth: The role of protective factors. Journal of Adolescent Health, 39(5), 662-668.

Esposito-Smythers, C., Spirito, A., Kahler, C. W., Hunt, J., \& Monti, P. (2011). Treatment of co-occurring substance abuse and suicidality among adolescents: A randomized trial. Journal of Consulting and Clinical Psychology, 79(6), 728-739.

Feder, M. M., \& Diamond, G. M. (2016). Parent-therapist alliance and parent attachmentpromoting behaviour in attachment-based family therapy for suicidal and depressed adolescents. Journal of Family Therapy, 38(1), 82-101. 
Feeny, N. C., Silva, S. G., Reinecke, M. A., McNulty, S., Findling, R. L., Rohde, P., March, J. S. (2009). An exploratory analysis of the impact of family functioning on treatment for depression in adolescents. Journal of Clinical Child and Adolescent Psychology, 38(6), 814-825.

Flouri, E., \& Buchanan, A. (2002). The protective role of parental involvement in adolescent suicide. Crisis, 23(1), 17-22.

Fonagy, P., \& Target, M. (2000). Mentalization and personality disorder in children: A current perspective from the Anna Freud Centre. In Annual Meeting of the Association for Child Psychoanalysis Inc., Mar, 1997, Cancun, Mexico; A shortened version of this chapter was presented. Taylor \& Francis.

Frey, L. M., \& Cerel, J. (2015). Risk for suicide and the role of family: A narrative review. Journal of Family Issues, 36(6), 716-736.

Fried, E. I., \& Nesse, R. M. (2015). Depression is not a consistent syndrome: an investigation of unique symptom patterns in the STAR* D study. Journal of Affective Disorders, 172, 96-102.

Garcia, C., Skay, C., Sieving, R., Naughton, S., \& Bearinger, L. H. (2008). Family and racial factors associated with suicide and emotional distress among Latino students. Journal of School Health, 78(9), 487-495.

Glenn, C. R., Franklin, J. C., \& Nock, M. K. (2015). Evidence-based psychosocial treatments for self-injurious thoughts and behaviors in youth. Journal of Clinical Child \& Adolescent Psychology, 44(1), 1-29.

Goldstein, T., Birmaher, B., Axelson, D., Goldstein, B., Gill, M. K., Esposito-Smythers, C., Ryan, N., ... Keller, M. (2009). Family environment and suicidal ideation among bipolar youth. Archives of Suicide Research, 13(4), 378-388.

Gomez, S. H., Tse, J., Wang, Y., Turner, B., Millner, A. J., Nock, M. K., \& Dunn, E. C. (2017). Are there sensitive periods when child maltreatment substantially elevates suicide risk? Results from a nationally representative sample of adolescents. Depression and Anxiety, 34(8), 734-741.

Greger, H. K., Myhre, A. K., Lydersen, S., \& Jozefiak, T. (2015). Previous maltreatment and present mental health in a high-risk adolescent population. Child Abuse \& Neglect, 45, 122-134.

Haynie, D. L., Petts, R. J., Maimon, D., \& Piquero, A. R. (2009). Exposure to violence in adolescence and precocious role exits. Journal of youth and adolescence, 38(3), 269-286.

Henggeler, S. W., Schoenwald, S. K., Rowland, M. D., \& Cunningham, P. B. (2002) Multisystemic treatment of children and adolescents with serious emotional disturbance. New York: Guilford.

Herres, J., Kodish, T., Fein, J., \& Diamond, G. S. (2017). Screening to identify groups of pediatric emergency department patients using latent class analysis of reported suicidal ideation and non-suicidal self-injury. Archives of Suicide Research, 1-12. https://doi.org/10.1080/13811118.2017.1283264

Holland, K. M., Vivolo-Kantor, A. M., Logan, J. E., \& Leemis, R. W. (2017). Antecedents of suicide among youth aged 11-15: A multistate mixed methods analysis. Journal of Youth and Adolescence, 46(7), 1598-1610.

Hoyert, D. L. (2012). 75 years of mortality in the United States, 1935-2010. US Department of Health and Human Services, Centers for Disease Control and Prevention, Nationa Center for Health Statistics.

Joiner, T. E. (2005). Why people die by suicide. Cambridge, MA: Harvard University Press

Kaminski, J. W., Puddy, R. W., Hall, D. M., Cashman, S. Y., Crosby, A. E., \& Ortega, L. A (2010). The relative influence of different domains of social connectedness on selfdirected violence in adolescence. Journal of Youth and Adolescence, 39(5), 460-473.

Kang, B. H., Kang, J. H., Park, H. A., Cho, Y. G., Hur, Y. I., Sim, W. Y., ... Kim, K. (2017) The mediating role of parental support in the relationship between life stress and suicidal ideation among middle school students. Korean Journal of Family Medicine, 38(4), 213.

Kerr, D. C., Preuss, L. J., \& King, C. A. (2006). Suicidal adolescents' social support from family and peers: Gender-specific associations with psychopathology. Journal of Abnormal Child Psychology, 34(1), 99-110.

Kidd, S., Henrich, C. C., Brookmeyer, K. A., Davidson, L., King, R. A., \& Shahar, G. (2006). The social context of adolescent suicide attempts: Interactive effects of parent, peer, and school social relations. Suicide and Life-threatening Behavior, 36(4), 386-395.

Kim, S., Sharp, C., \& Carbone, C. (2014). The protective role of attachment security for adolescent borderline personality disorder features via enhanced positive emotion regulation strategies. Personality Disorders: Theory, Research, and Treatment, 5(2), 125-136.

King, R. A., Schwab-Stone, M., Flisher, A. J., Greenwald, S., Kramer, R. A., Goodman, S. H., ... Gould, M. S. (2001). Psychosocial and risk behavior correlates of youth suicide attempts and suicidal ideation. Journal of the American Academy of Child \& Adolescent Psychiatry, 40(7), 837-846.

King, C. A., Kerr, D. C., Passarelli, M. N., Foster, C. E., \& Merchant, C. R. (2010). One-year follow-up of suicidal adolescents: Parental history of mental health problems and time to post-hospitalization attempt. Journal of Youth and Adolescence, 39(3), 219-232.

Kobak, R., Cassidy, J., Lyons-Ruth, K., \& Ziv, Y. (2006). Attachment, stress, and psychopathology: A developmental pathways model. In D. Cicchetti, \& D. J. Cohen (Eds.), Vol. 2006. Handbook of developmental psychopathology (pp. 333-369). Cambridge: Cambridge University Press.

Kobak, R., \& Herres, J. (2012). Social networks and attachment bonds during adolescence: Implications for early pair bonding and risky behaviors. In L. Campbell, \& T. J. Loving (Eds.), Interdisciplinary research on close relationships: The case for integration (pp. 135-152). Washington, DC: American Psychological Association.

Kobak, R., Rosenthal, N. L., Zajac, K., \& Madsen, S. D. (2007). Adolescent attachment hierarchies and the search for an adult pair-bond. New Directions for Child and Adolescent Development, 117, 57-72.
Kobak, R. R., Cole, H. E., Ferenz-Gillies, R., Fleming, W. S., \& Gamble, W. (1993). Attachment and emotion regulation during mother-teen problem solving: A control theory analysis. Child Development, 64(1), 231-245.

Lai, K. W., \& McBride-Chang, C. (2001). Suicidal ideation, parenting style, and family climate among Hong Kong adolescents. International Journal of Psychology, 36(2), $81-87$.

Lee, A., \& Hankin, B. L. (2009). Insecure attachment, dysfunctional attitudes, and low self-esteem predicting prospective symptoms of depression and anxiety during adolescence. Journal of Clinical Child \& Adolescent Psychology, 38(2), 219-231.

Lee, M. T., Wong, B. P., Chow, B. W. Y., \& McBride-Chang, C. (2006). Predictors of suicide ideation and depression in Hong Kong adolescents: Perceptions of academic and family climates. Suicide and Life-threatening Behavior, 36(1), 82-96.

Lerner, R. M., \& Steinberg, L. (2009). Handbook of adolescent psychology, individual bases of adolescent development (Vol. 1). New Jersey: John Wiley \& Sons.

Linehan, M. M. (1993a). Cognitive-behavioral treatment of borderline personality disorder. New York: Guilford Press.

Linehan, M. M. (1993b). Skills training manual for treating borderline personality disorder. New York: Guilford Press.

Liu, X., Sun, Z., \& Yang, Y. (2008). Parent-reported suicidal behavior and correlates among adolescents in China. Journal of Affective Disorders, 105(1-3), 73-80.

Madu, S. N., \& Matla, M. P. (2004). Family environmental factors as correlates for adolescent suicidal behaviors in the Limpopo Province of South Africa. Social Behavior and Personality, 32, 341-354.

Machell, K. A., Rallis, B. A., \& Esposito-Smythers, C. (2016). Family environment as a moderator of the association between anxiety and suicidal ideation. Journal of Anxiety Disorders, 40, 1-7.

Martin, G., \& Waite, S. (1994). Parental bonding and vulnerability to adolescent suicide. Acta Psychiatrica Scandinavica, 89(4), 246-254.

Miller, A. L., Glinski, J., Woodberry, K. A., Mitchell, A. G., \& Indik, J. (2002). Family therapy and dialectical behavior therapy with adolescents: Part I: Proposing a clinical synthesis. American Journal of Psychotherapy, 56(4), 568-584.

Miller, A. L., Rathus, J. H., Linehan, M. M., Wetzler, S., \& Leigh, E. (1997). Dialectical behavior therapy adapted for suicidal adolescents. Journal of Practical Psychiatry \& Behavioral Health, 3(2), 78-86.

Miller, Rathus, \& Linehan. (2007). Dialectical behavior therapy with suicidal adolescents. New York: Guilford Press.

Nock, M. K., Green, J. G., Hwang, I., McLaughlin, K. A., Sampson, N. A., Zaslavsky, A. M. \& Kessler, R. C. (2013). Prevalence, correlates, and treatment of lifetime suicidal behavior among adolescents: Results from the national comorbidity survey replication adolescent supplement. JAMA Psychiatry, 70(3), 300-310.

Olson, D. H., Sprenkle, D. H., \& Russell, C. S. (1979). Circumplex model of marital and family systems: I. Cohesion and adaptability dimensions, family types, and clinical applications. Family Process, 18(1), 3-28.

Ougrin, D., Tranah, T., Stahl, D., Moran, P., \& Asarnow, J. R. (2015). Therapeutic interventions for suicide attempts and self-harm in adolescents: Systematic review and meta-analysis. Journal of the American Academy of Child \& Adolescent Psychiatry, 54(2), 97-107.

Peña, J. B., Kuhlberg, J. A., Zayas, L. H., Baumann, A. A., \& Gulbas, L. (2011). Familism, family environment, and suicide attempts among Latina youth. Suicide and Lifethreatening Behavior, 41(3), 330-341.

Perkins, D. F. \& Hartless, G. (2002). An ecological risk-factor examination of suicide ideation and behavior of adolescents. Journal of Adolescent Research, 17(1), 3-26.

Racz, S. J., \& McMahon, R. J. (2011). The relationship between parental knowledge and monitoring and child and adolescent conduct problems: A 10-year update. Clinical Child and Family Psychology Review, 14(4), 377-398.

Randell, B. P., Wang, W. L., Herting, J. R., \& Eggert, L. L. (2006a). Family factors predicting categories of suicide risk. Journal of Child and Family Studies, 15(3), 247-262.

Randell, B. P., Wang, W., Herting, J. R., \& Eggert, L. L. (2006b). Family factors predicting categories of suicide risk. Journal of Child and Family Studies, 15(3), 255-270.

Rapp, A. M., Lau, A., \& Chavira, D. A. (2017). Differential associations between social anxiety disorder, family cohesion, and suicidality across racial/ethnic groups: Findings from the National Comorbidity Survey-Adolescent (NCS-A). Journal of Anxiety Disorders, 48, 13-21.

Rathus, J. H., \& Miller, A. L. (2002). Dialectical behavior therapy adapted for suicidal adolescents. Suicide and Life-threatening Behavior, 32(2), 146-157.

Reardon, S. (2014). NIH rethinks psychiatry trials. Nature News, 507(7492), 288.

Resnick, M. D., Bearman, P. S., Blum, R. W., Bauman, K. E., Harris, K. M., Jones, J., Udry, J. R. (1997). Protecting adolescents from harm: Findings from the National Longitudinal Study on Adolescent Health. Jama, 278(10), 823-832.

Rossouw, T. I., \& Fonagy, P. (2012). Mentalization-based treatment for self-harm in adolescents: A randomized controlled trial. Journal of the American Academy of Child \& Adolescent Psychiatry, 51(12), 1304-1313.

Rubenstein, J. L., Halton, A., Kasten, L., Rubin, C., \& Stechler, G. (1998). Suicidal behavior in adolescents. American Journal of Orthopsychiatry, 68(2), 274-284.

Rudd, M. D. (2000). The suicidal mode: a cognitive-behavioral model of suicidality. Suicide \& Life-Threatening Behavior, 30(1), 18-33.

Saffer, B. Y., \& Klonsky, E. D. (2014). Parental Bonding and Risk for Suicide in Adolescents.

Sroufe, A. L. (2005). Attachment and development: A prospective, longitudinal study from birth to adulthood. Attachment \& Human Development, 7(4), 349-367.

Stanley, B., Brown, G., Brent, D. A., Wells, K., Poling, K., Curry, J., ... Hughes, J. (2009). Cognitive-behavioral therapy for suicide prevention (CBT-SP): Treatment model, feasibility, and acceptability. Journal of the American Academy of Child \& Adolescent Psychiatry, 48(10), 1005-1013.

Steele, H., \& Steele, M. (Eds.). (2017). Handbook of attachment-based interventions. Guilford Publications. 
Steinberg, L. (1990). Autonomy, conflict, and harmony in the family relationship. In S. S. Feldman, \& G. R. Elliott (Eds.), At the threshold: The developing adolescent (pp. 255-276). Harvard University Press.

Tang, T., Ko, C., Yen, J., Lin, H., Liu, S., Huang, C., \& Yen, C. (2009). Suicide and its association with individual, family, peer, and school factors in an adolescent population in southern Taiwan. Suicide and Life-threatening Behavior, 39(1), 91-102.

Tomori, M., Kienhorst, C. W. M., De Wilde, E. J., \& Van Den Bout, J. (2001). Suicidal behaviour and family factors among Dutch and Slovenian high school students: a comparison. Acta Psychiatrica Scandinavica, 104(3), 198-203.

Toumbourou, J. W., \& Gregg, M. E. (2002). Impact of an empowerment-based parent education program on the reduction of youth suicide risk factors. Journal of Adolescent Health, 31(3), 277-285.

Van Durme, K., Braet, C., \& Goossens, L. (2015). Insecure attachment and eating pathology in early adolescence: Role of emotion regulation. The Journal of Early Adolescence, 35(1), 54-78.

Van Orden, K. A., Witte, T. K., Cukrowicz, K. C., Braithwaite, S. R., Selby, E. A., \& Joiner, T. E., Jr. (2010). The interpersonal theory of suicide. Psychological Review, 117(2), 575.

Vitiello, B., Brent, D. A., Greenhill, L. L., Emslie, G., Wells, K., Walkup, J. T., ... Zelazny, J. (2009). Depressive symptoms and clinical status during the Treatment of Adolescent Suicide Attempters (TASA) study. Journal of the American Academy of Child \& Adolescent Psychiatry, 48(10), 997-1004.

Wagner, B. M., Silverman, M. A. C., \& Martin, C. E. (2003). Family factors in youth suicidal behaviors. American Behavioral Scientist, 46(9), 1171-1191.

Wan, G. W. Y., \& Leung, P. W. L. (2010). Factors accounting for youth suicide attempt in Hong Kong: A model building. Journal of Adolescence, 33, 575-582.

Wang, C., La Salle, T., Wu, C., Do, K. A., \& Sullivan, K. E. (2018). School climate and parental involvement buffer the risk of peer victimization on suicidal thoughts and behaviors among Asian American middle school students. Asian American Journal of Psychology, 9(4), 296.
Wells, K. C., \& Albano, A. M. (2005). Parent involvement in CBT treatment of adolescent depression: Experiences in the treatment for adolescents with depression study (TADS). Cognitive and Behavioral Practice, 12(2), 209-220.

Wells, K. C., \& Heilbron, N. (2012). Family-based cognitive-behavioral treatments for suicidal adolescents and their integration with individual treatment. Cognitive and Behavioral Practice, 19(2), 301-314.

Whitlock, J., Wyman, P. A., \& Moore, S. R. (2014). Connectedness and suicide prevention in adolescents: Pathways and implications. Suicide \& Life-Threatening Behavior, 44(3), 246-272.

Woodberry, K. A., Miller, A. L., Glinski, J., Indik, J., \& Mitchell, A. G. (2002). Family therapy and dialectical behavior therapy with adolescents: Part II: A theoretical review. American Journal of Psychotherapy, 56(4), 585-602.

Wong, I. N., De Man, A. F., \& Leung, P. W. (2002). Perceived parental child rearing and suicidal ideation in Chinese adolescents. Social Behavior and Personality: An International Journal, 30(1), 19-24.

Xing, X., Tao, F., Wan, Y., Xing, C., Qi, X., Hao, J., ... Huang, L. (2010). Family factors associated with suicide attempts among Chinese adolescent students: A national cross-sectional survey. Journal of Adolescent Health, 46(6), 592-599.

Yoder, K. A., \& Hoyt, D. R. (2005). Family economic pressure and adolescent suicidal ideation: application of the family stress model. Suicide and Life-threatening Behavior, 35(3), 251-264.

Zhang, J., \& Jin, S. (1996). Determinants of suicide ideation: A comparison of Chinese and American college students. Adolescence, 31(122), 451.

Zimmerman, G. M. (2013). Does violence toward others affect violence toward oneself? Examining the direct and moderating effects of violence on suicidal behavior. Social Problems, 60(3), 357-382.

Zisk, A., Abbott, C. H., Bounoua, N., Diamond, G. S., \& Kobak, R. (2019). Parent-teen communication predicts treatment benefit for depressed and suicidal adolescents. Journal of Consulting and Clinical Psychology, 87(12), 1137-1148. 